\title{
Metabolomic Biomarkers for Obesity in Humans: A Short Review
}

\author{
Sebastian Rauschert Olaf Uhl Berthold Koletzko Christian Hellmuth \\ Division of Metabolic and Nutritional Medicine, Dr. von Hauner Children's Hospital, Ludwig Maximilian University of \\ Munich, Munich, Germany
}

\section{Key Words}

Obesity · Metabolomics • Branched-chain amino acids .

Fatty acids $\cdot \beta$-Oxidation

\begin{abstract}
Background: The prevalence and incidence of obesity have become a major public health problem during the last decades, but the underlying biochemical and metabolic processes are not fully understood. Metabolomics, the science of small molecules of the metabolism, is helping to unravel these mechanisms via the identification of markers related to obesity. These biomarkers are used to prevent diseases in later life or for the early diagnosis of diseases. This review focuses on articles dealing with biomarkers for obesity. Key Messages: Branched-chain amino acids (BCAA), nonesterified fatty acids, organic acids, acylcarnitines, and phospholipids were identified as potential biomarkers for obesity. This indicates a relation between elevated BCAA, and other amino acids, and the obese state. Furthermore, deregulation of $\beta$-oxidation is associated with the development of obesity. The results have several limitations, including the differing ages of the subjects in the studies, the fact that all of the studies had a case-control design and therefore no causal explanatory power, and that most looked for similar metabolites and reported almost equal results. Conclusion: The strength of this review is that it gives a comprehensive over-
\end{abstract}

view of the current status of the knowledge on metabolomics biomarkers for obesity, but further research is needed because the methods used in the studies to date are very homogenous, e.g. most used a targeted approach and therefore analyzed almost the same group of metabolites. Moreover, prospective studies are lacking since all of the studies are either case-control or cross-sectional studies.

(c) 2014 S. Karger AG, Basel

\section{Introduction}

In the last decades, obesity has become a global public health burden in developed as well as in developing countries $[1,2]$. Obesity, as a worldwide growing epidemic, raises the need for better tools to monitor the disease adequately and to enable better strategies for early prevention and diagnosis.

The increasing number of obese people in industrialized countries is mainly related to modern lifestyle factors, including nutrition and leisure time activities. The strong association of obesity with type 2 diabetes (T2DM) [3], hypertension [4], and metabolic syndrome [5] high-

The data presented are part of the PhD thesis written by Sebastian Rauschert at the Medical Faculty of the Ludwig Maximilian University of Munich.

\section{KARGER}

E-Mail karger@karger.com

www.karger.com/anm
(C) 2014 S. Karger AG, Basel

0250-6807/14/0644-0314\$39.50/0 
lights the need to investigate the development and persistence of obesity. To handle obesity and its consequences, it is necessary to understand the underlying mechanisms of its pathology and its relation to nutrition.

Unraveling the underlying mechanisms is also of special interest in relation to the hypothesis of early programming, which suggests that a high dietary protein content in early life leads to a greater weight gain and rapid growth in the first 2 years of life, which is further related to later obesity [6]. To prevent adverse effects of early-life nutrition, one can search for biomarkers that represent the risk for the development of later diseases including obesity, T2DM, and metabolic syndrome. These biomarkers can be used for routine measurement of therapeutic or preventive responses. They can be found in body fluids such as blood or urine and can be small biological molecules, also called metabolites. The existing literature on metabolic precursors in obesity mainly comprises comparisons between lean and obese subjects and only a few focus on the metabolic precursors and alterations underlying the obese phenotype, but this is of major interest. Predicting future health outcomes by investigating the metabolic phenotype, as is routinely performed in newborn screening [7], would be a major benefit for the prevention of obesity and insulin resistance in later life.

One tool to search for biomarkers is targeted metabolomics. Metabolomics examines the human metabolome to detect metabolites (small molecules with a molecular weight of less than $1,500 \mathrm{Da}$ ) [8], metabolic pathways, and their impairments. Therefore, biofluids, tissues, or extracts from cells are analyzed. The aim of many metabolomics studies is to find highly predictive markers for pathophysiological processes or specific metabolic states.

The objective of this review is to present a comprehensive overview of the current state of metabolomics changes due to obesity in humans to provide insight into the process of obesity development and the influence of obesity on insulin signaling on a molecular level. The aim was to identify specific articles dealing with the topic of analysis of the human metabolome using a metabolomics approach involving biomarkers for obesity or pre-obesity.

\section{Methods}

\section{Literature Search Strategy}

The literature search was conducted in the PubMed database (National Center for Biotechnology Information, US National Library of Medicine), due to its medical, biochemical, biological, and statistical content, from database inception to February 2014. The search was limited to papers with the full text available, written in
English, and reporting on human beings in the setting of PubMed. There were no limitations for study design or population age.

'Obesity' and its synonym 'adiposity' were the central search terms, together with 'metabolome' and its variants. The following 5 steps were performed during the search on PubMed, using different combinations of search terms.

The terms for the first step (1) were 'Obesity or Adiposity and Metabolomic\$' and resulted in 97 hits. The second step (2) consisted of the combination of 'Obesity or Adiposity and Metabol* and Biomarker and Metabolomics', resulting in 30 hits. The next step (3) was 'Obesity or Adiposity and Metabol* and Biomarker not Metabolic Syndrome not Diabetes not Cancer not Gene* not Cardiovascular Disease not Insulin Resistance', with 572 resulting hits. The reason for the exclusion of health conditions like 'metabolic syndrome', 'cancer', 'cardiovascular disease', and 'insulin resistance' is that this review focused on obesity only and the first 2 steps resulted in many articles focusing on other health conditions. The next step (4) was 'Obesity or Adiposity and Biomarker not Metabolic Syndrome not Diabetes not Cancer not Gene* not Cardiovascular Disease not Insulin Resistance' (955 hits), and the last step (5) was 'Obes* or Adiposity and Metabol* and Biomarker not Gene* not Cancer not Diabetes not 'Metabolic Syndrome' not 'Cardiovascular Disease' not Nutri* not 'Insulin Resistance”, resulting in 644 hits. The difference with the second search step was the exclusion of the exact phrases of the health condition, which is represented by the quotation marks. Additionally, 'Gene' and some variants were also excluded because the methodological focus lies on the metabolomics approach.

After performance of the literature review, the reference lists from the relevant reports and reviews were searched by hand for studies which were of additional interest (snowball literature search).

Another step was the search in the journal Metabolomics, because this journal cannot be searched via the PubMed database but might yield some further publications on the topic.

\section{Selection Criteria}

At first, the titles and abstracts of all references were screened according to the inclusion criteria. Articles were included independently of the study design. Studies were included in the analysis if they: (1) were conducted in human populations (this had to be done a second time, because limitation of the settings on PubMed still resulted in some animal studies), (2) performed either a targeted or an untargeted metabolomics analysis, (3) included an analysis done with plasma or serum samples, and (4) focused on biomarkers for obesity. Studies were excluded if they were categorized as descriptive reviews or editorials.

\section{Articles Finally Included}

Initially, 1,254 articles were included. Those records were screened and 1,142 articles were excluded due to the fact that their topics were not relevant or eligible for the research question of this review, meaning that they focused on other health conditions such as insulin resistance, cancer, or diabetes, were not metabolomics studies, or analyzed the effect of a specific nutrition on metabolism or health. Of the remaining 112 articles, 16 were included after reading of the abstracts, but 3 more were excluded because they were review articles, which was not apparent in the first screening step. Finally and after reading the full text of the articles, 13 papers were included (with 2 papers resulting from the snowball literature search and 1 resulting from the search in the Metabolomics jour- 
Fig. 1. Flow diagram of the literature review.

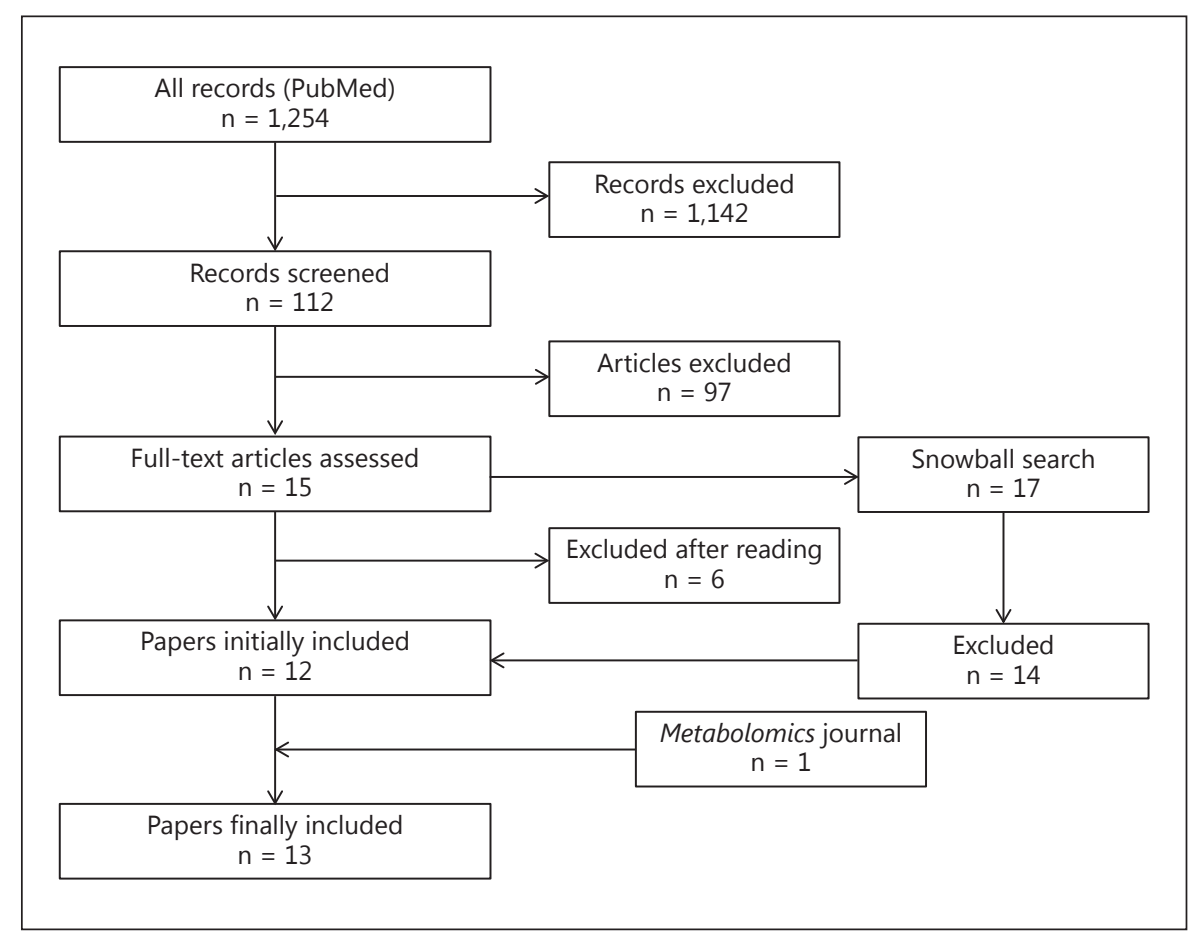

nal). The individual steps of the literature review are shown in figure 1 and a comprehensive overview of the included articles is presented in table 1 .

\section{Metabolite Nomenclature}

Fatty acids (FA), nonesterified FA (NEFA), acylcarnitines (CN), cholesteryl ester (CE), lysophosphatidylcholines (LPC), and phosphatidylcholines (PC) are mentioned as CXX:Y. In this nomenclature, $\mathrm{XX}$ is the length of the carbon chain, $\mathrm{Y}$ is the number of double bonds, and $\mathrm{OH}$ in the formula means that the molecule contains a hydroxyl group. 'a' means that the acyl chain is bound via an ester bond to the backbone. ' $\uparrow$ ' means higher concentrations in obese populations and positive associations with a marker for obesity, and ' $\downarrow$ ' means the opposite.

\section{Results}

The main results of all of the finally included articles were changes in the $\beta$-oxidation of FA and elevations of branched-chain amino acids (BCAA). Most of the studies $(\mathrm{n}=8)$ analyzed serum samples.

Seven studies were performed with adults as the study population, and 5 were done in children. The main design was case-control, which means the results cannot be interpreted in a causal way and should rather been viewed as associations. An overview of the results of the different studies is given in table 1 . The study characteristics can be found in table 2 .

\section{Acylcarnitines}

Four studies observed alterations of several CN levels. Oberbach et al. [9], for example, discovered changes in the levels of C2-CN ( $\downarrow), \mathrm{C} 10: 1-\mathrm{CN}(\uparrow), \mathrm{C} 14: 1-\mathrm{OH}-\mathrm{CN}$ $(\uparrow), \mathrm{C} 14: 2-\mathrm{CN}(\uparrow), \mathrm{C} 18: 1-\mathrm{CN}(\uparrow)$, and C18:2-CN $(\uparrow)$ by analyzing the blood of the subjects after $1 \mathrm{~h}$ of exercise. Mihalik et al. [10] observed alterations of free $\mathrm{CN}$, C14:1-CN ( $\uparrow), \mathrm{C} 16-\mathrm{CN}(\uparrow), \mathrm{C} 18-\mathrm{CN}(\uparrow)$, and C18:1-CN $(\uparrow)$. Wahl et al. [11] reported significant differences in C12:1-CN $(\uparrow)$ and C16:1-CN $(\uparrow)$ between lean and obese subjects, and Newgard et al. [12] analyzed the blood of adult subjects with median BMI values of 23.2 (lean) and 36.6 (obese) and discovered alterations in $4 \mathrm{CN}$ species, i.e. $\mathrm{C} 3-\mathrm{CN}(\uparrow), \mathrm{C} 5-\mathrm{CN}(\uparrow), \mathrm{C} 6-\mathrm{CN}(\uparrow)$, and $\mathrm{C} 8: 1-\mathrm{CN}(\uparrow)$.

An article by Moore et al. [13] found elevations in C3$\mathrm{CN}, \mathrm{C} 5-\mathrm{CN}$, and C6-CN, and another showed alterations in L-carnitine ( $\downarrow$ ), C3-CN $(\uparrow)$, and C4-CN $(\uparrow)$ [14].

$\mathrm{CN}$ with 3 , 4, or 5 carbon atoms are derived from BCAA metabolism or other amino acids (AA), while even-chain $\mathrm{CN}$ result from $\beta$-oxidation.

A possible explanation for the alterations in middle and long even-chain $\mathrm{CN}$ levels is their central role in the transport of FA into the mitochondria where FA undergo $\beta$-oxidation. The transport form of NEFA, acyl-CoA, is converted to $\mathrm{CN}$ by carnitine-palmitoyltransferase 1 (CPT1) to facilitate entry into the mitochondria. After entering the mitochondria, the $\mathrm{CN}$ is reconverted to acyl- 


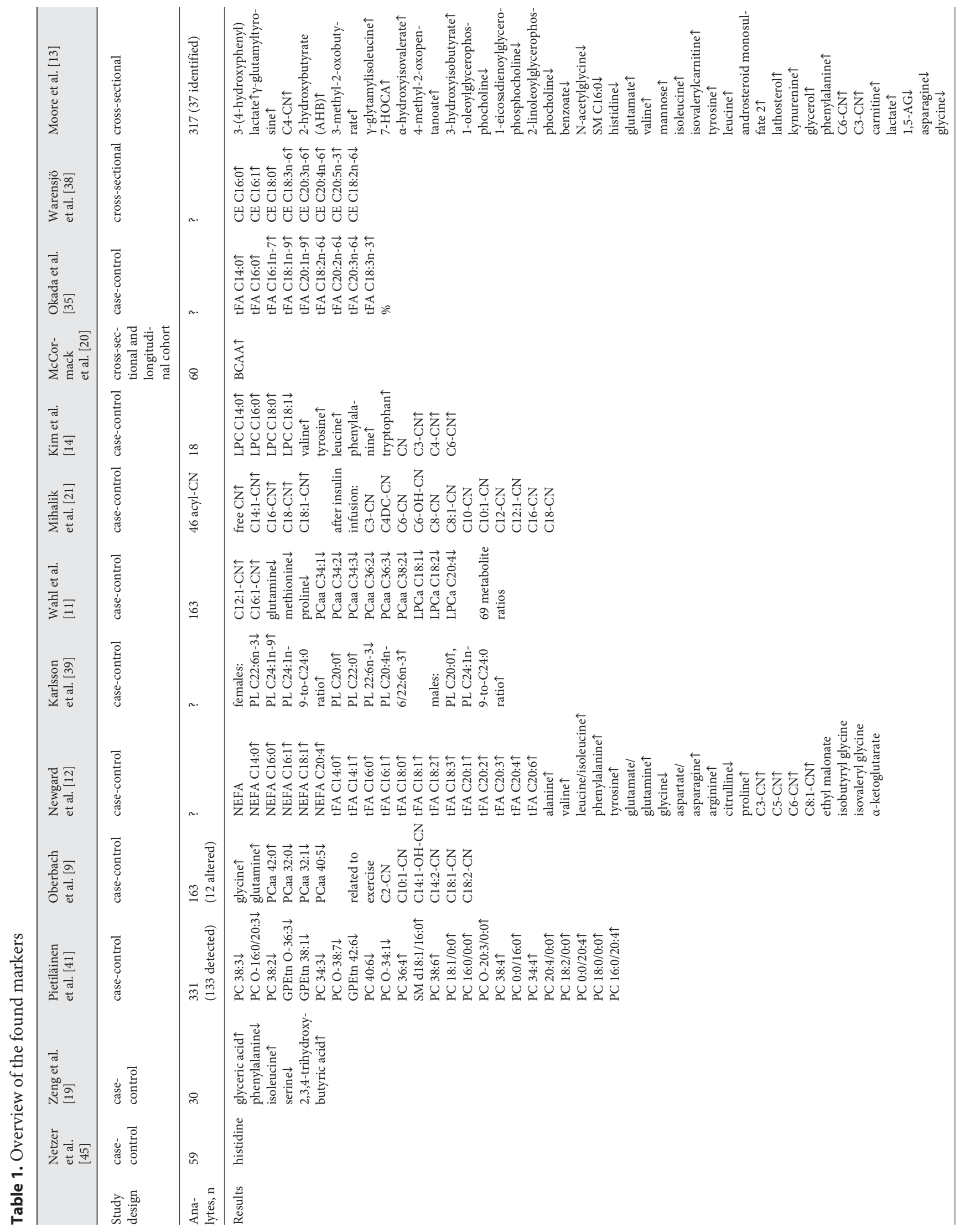




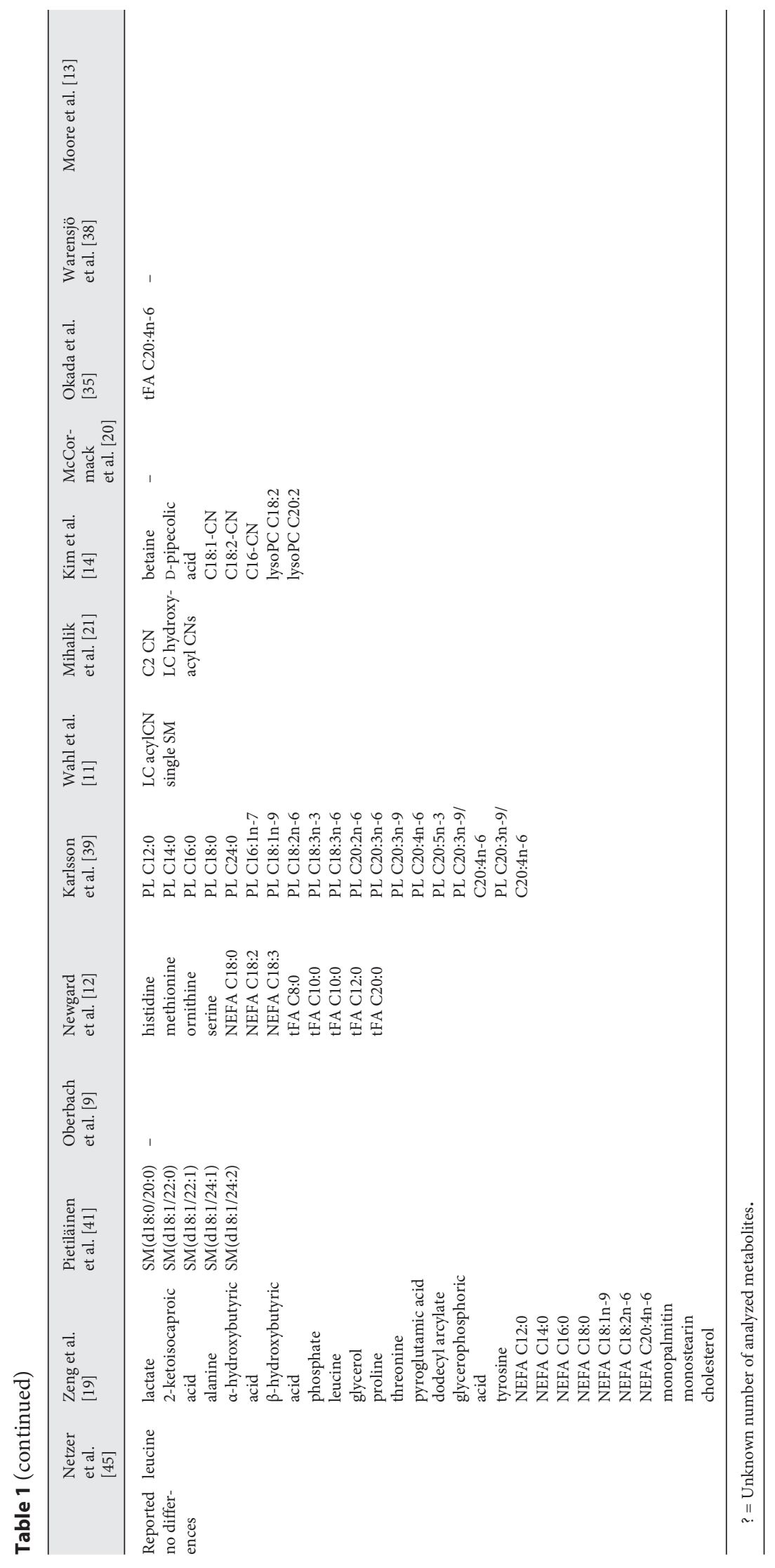


Table 2. Study characteristics

\begin{tabular}{|c|c|c|c|c|}
\hline Reference & Study type & Age, years & BMI & Sample type fasted \\
\hline Netzer et al. [45] & case-control & $\begin{array}{l}\text { lean: } 38.33 \pm 7.16 \\
\text { obese: } 46.27 \pm 10.48\end{array}$ & $\begin{array}{l}\text { lean: } 23.88 \pm 2.50(n=30) \\
\text { obese: } 34.18 \pm 2.78(n=22)\end{array}$ & not reported \\
\hline Zeng et al. [19] & case-control & $\begin{array}{l}\text { lean: } 8.7 \pm 1.74 \\
\text { overweight: } 10.0 \pm 1.15 \\
\text { obese: } 8.9 \pm 2.14\end{array}$ & $\begin{array}{l}\text { lean: } 16.6 \pm 1.46(n=16) \\
\text { overweight: } 22.4 \pm 2.65(n=13) \\
\text { obese: } 24.6 \pm 3.44(n=32)\end{array}$ & $\begin{array}{l}\text { plasma samples } \\
\text { not reported if fasted }\end{array}$ \\
\hline Pietiläinen et al. [41] & case-control & not reported & $\begin{array}{l}\text { lean: } 25.4(24.5-26.1)(\mathrm{n}=7) \\
\text { obese: } 30.4(28.4-32.5)(\mathrm{n}=39 \text { males } \\
\text { and } 20 \text { females })\end{array}$ & $\begin{array}{l}\text { serum samples } \\
\text { overnight fast } \\
(8.00 \text { a.m.) }\end{array}$ \\
\hline Oberbach et al. [9] & case-control & $\begin{array}{l}\text { lean: } 23.7 \pm 1.99(20-27) \\
\text { obese: } 24.1 \pm 3.11(20-30)\end{array}$ & $\begin{array}{l}\text { lean: } 23-25(n=15) \\
\text { obese: } 30-45(n=15)\end{array}$ & $\begin{array}{l}\text { serum samples } \\
\text { overnight fast } \\
(8.00-10.00 \text { a.m. })\end{array}$ \\
\hline Newgard et al. [12] & case-control & $\begin{array}{l}\text { lean: } 50(38-60) \\
\text { obese: } 52(46-60)\end{array}$ & $\begin{array}{l}\text { lean: median } 23.2(\mathrm{n}=67) \\
\text { obese: } \text { median } 36.6(\mathrm{n}=74)\end{array}$ & $\begin{array}{l}\text { plasma samples } \\
\text { overnight fast } \\
(<10.00 \text { a.m. })\end{array}$ \\
\hline Karlsson et al. [39] & case-control & $\begin{array}{l}\text { lean women: } 12.4(11.7-14.5) \\
\text { lean men: } 12.6(11.3-15.4) \\
\text { obese women: } 15.0(11.3-16.4) \\
\text { obese men: } 11.4(10.4-15.4)\end{array}$ & $\begin{array}{l}\text { lean women: } 29.8-40.4(n=5) \\
\text { lean men: } 26.8-35.3(n=5) \\
\text { obese women: } 17.9-23.4(n=9) \\
\text { obese men: } 17.1-23.2(n=6)\end{array}$ & $\begin{array}{l}\text { plasma samples } \\
\text { overnight fast } \\
(12 \mathrm{~h})\end{array}$ \\
\hline Wahl et al. [11] & case-control & $\begin{array}{l}\text { lean: } 11.1 \pm 2.8 \\
\text { obese: } 10.9 \pm 2.1\end{array}$ & $\begin{array}{l}\text { lean: } 17.2 \pm 2.1(n=40) \\
\text { obese: } 27.7 \pm 4.0(n=80)\end{array}$ & $\begin{array}{l}\text { serum samples } \\
\text { overnight fast } \\
(8.00 \text { a.m.) }\end{array}$ \\
\hline Mihalik et al. [21] & case-control & $\begin{array}{l}\text { lean: } 47 \pm 7 \\
\text { obese: } 43 \pm 7\end{array}$ & $\begin{array}{l}\text { lean: } 23.9 \pm 1.8(n=12) \\
\text { obese: } 34.3 \pm 3.1(n=14)\end{array}$ & $\begin{array}{l}\text { plasma samples } \\
\text { overnight fast } \\
(10-12 \mathrm{~h})\end{array}$ \\
\hline Kim et al. [14] & case-control & $\begin{array}{l}\text { lean: } 39.5 \pm 1.22 \\
\text { obese: } 39.6 \pm 1.24\end{array}$ & $\begin{array}{l}\text { lean: } 20.9 \pm 0.14(n=30) \\
\text { obese: } 28.9 \pm 0.20(n=30)\end{array}$ & $\begin{array}{l}\text { plasma samples } \\
\text { overnight fast }(12 \mathrm{~h})\end{array}$ \\
\hline $\begin{array}{l}\text { McCormack et al. } \\
{[20]}\end{array}$ & $\begin{array}{l}\text { cross-sectional } \\
\text { and } \\
\text { longitudinal } \\
\text { cohort }\end{array}$ & $\begin{array}{l}\text { obese cross-sectional: } 13.3 \pm 2.9 \\
\text { obese longitudinal cohort: } 11.0 \pm 1.6 \\
\text { obese longitudinal cohort follow-up: } \\
12.5 \pm 1.6\end{array}$ & $\begin{array}{l}\text { obese cross-sectional: } 24.9 \pm 7.4(n=69) \\
\text { obese longitudinal cohort: } 26.0 \pm 7.1 \\
(n=17) \\
\text { obese longitudinal cohort follow-up: } \\
27.9 \pm 7.6(n=17)\end{array}$ & $\begin{array}{l}\text { plasma samples } \\
\text { overnight fast }\end{array}$ \\
\hline Okada et al. [35] & case-control & $\begin{array}{l}\text { lean: } 12.6 \pm 0.5 \\
\text { obese: } 11.8 \pm 3.8\end{array}$ & $\begin{array}{l}\text { lean: } 17.9 \pm 1.7(\mathrm{n}=25 \text { males and } 28 \\
\text { females) } \\
\text { obese: } 29.5 \pm 4.9(\mathrm{n}=39 \text { males and } 20 \\
\text { females })\end{array}$ & $\begin{array}{l}\text { plasma samples } \\
\text { overnight fast }\end{array}$ \\
\hline Warensjö et al. [38] & cross-sectional & $\begin{array}{l}\text { obese women: } 40.6 \pm 9.9 \\
\text { obese men: } 40.6 \pm 9.1\end{array}$ & $\begin{array}{l}\text { obese women: } 23.7 \pm 3.8 \\
(\mathrm{n}=295) \\
\text { obese men: } 24.7 \pm 3.2 \\
(\mathrm{n}=554)\end{array}$ & $\begin{array}{l}\text { plasma samples } \\
\text { overnight fast } \\
(12 \mathrm{~h})\end{array}$ \\
\hline Moore et al. [13] & $\begin{array}{l}\text { case-control } \\
\text { (PLCO study) } \\
\text { case-control } \\
\text { (Navy study) } \\
\text { case-control } \\
\text { (Shanghai } \\
\text { physical activity } \\
\text { study) }\end{array}$ & $\begin{array}{l}55-74 \\
18-74 \\
\text { women: } 40-75 \\
\text { men: } 40-75\end{array}$ & not exactly reported & $\begin{array}{l}\text { serum samples } \\
\text { nonfasting } \\
\text { serum samples } \\
\text { nonfasting } \\
\text { plasma samples } \\
\text { fasted }\end{array}$ \\
\hline
\end{tabular}

Values are presented as means $\pm S D$, ranges, or medians (IQR) unless otherwise stated. 
CoA by CPT2, which is located in the inner membrane of the mitochondria. This CoA ester can then undergo $\beta$-oxidation.

$\mathrm{CN}$ can also cross the mitochondrial membrane in the other direction. After $\mathrm{CN}$ have left the mitochondria, they are excreted by either urine or bile. This detoxification plays a major role in cases of accumulation of acyl-CoA. Increasing levels of $\mathrm{CN}$ can be indicative of disorders of mitochondrial $\beta$-oxidation. This pathway may play a role in the development of T2DM and IR. One theory is that lipid oversupply results in saturation of the capacity of the mitochondria to oxidize FA. In this case, the mitochondrion becomes overloaded with FA, reflected by increased levels of $\mathrm{CN}$ in the plasma and decreased free carnitine levels [15]. If $\beta$-oxidation fails to degrade the excess FA, this leads to aggregation of free FA or acyl-CoA in the plasma, which can be converted to other lipids such as ceramides or diacylglycerols, which have been related to the development of insulin resistance [16]. In another hypothesis, FA oxidation is increased and overcomes the capacity of the TCA cycle to degrade acetyl-CoA. This results in a tailback of $\beta$-oxidation and an accumulation of short-chain $\mathrm{CN}$, also in oxidized and hydroxyl forms. These $\mathrm{CN}$ may also contribute to insulin resistance.

Carnitine plays another role in human metabolism. It is necessary not only for the oxidation of medium- and long-chain FA but also for the oxidation of BCAA [17]. C3-CN and C5-CN are by-products of the BCAA catabolism, providing a rationale for the elevation of these metabolites reported in some of the studies.

A study in rats led to the conclusion that carnitine stimulates the oxidation of BCAA by increasing the conversion of their keto analogues into carnitine esters and mitochondrial carnitine acyltransferase and then catalyzes the formation of $\mathrm{C} 3-\mathrm{CN}$ and branched-chain $\mathrm{CN}$ from BCAA [18].

The accumulation of different $\mathrm{CN}$ and BCAA in addition to the accumulation of FA degradation products could thus be interpreted according to their relation discussed above.

\section{Branched-Chain AA}

Four of the studies observed alterations in BCAA metabolism. Zeng et al. [19] found altered isoleucine ( $\uparrow$ ) in blood by examining lean, overweight, and obese children. Kim et al. [14] observed alterations in L-valine ( $\uparrow)$ and L-leucine $(\uparrow)$ in their comparison of lean and obese adults (aged 39-40 years). Moore et al. [13] found elevations in all 3 BCAA in obese adults. McCormack et al.
[20] observed elevated concentrations of leucine ( $\uparrow$ ), isoleucine $(\uparrow)$, and valine $(\uparrow)$ in 3 obese groups of children.

Wahl et al. [11] analyzed blood of children and found no alterations in BCAA metabolism. They argued that children may exhibit early adaptive mechanisms that preserve a normal BCAA metabolism in the presence of obesity and disturbed insulin sensitivity. Mihalik et al. [21] pointed out that the lower plasma BCAA in children may be due to an increased gluconeogenetic drive typically seen in diabetes.

However, more usually BCAA are elevated in obese subjects. Cheng et al. [22] discovered a possible relation between the BCAA leucine and $\beta$-oxidation. Goichon et al. [23] found that leucine supplementation altered the expression of several duodenal mucosal proteins, which are mainly involved in lipid metabolism. Therefore, the finding of elevated BCAA in obese persons with an assumed higher fat mass seems plausible.

Several articles indicated that elevated BCAA are signal molecules for enhanced protein synthesis [24] and are related to insulin resistance via the mTOR pathway $[12,25]$. In a recent review, Adams [26] showed that obesity, insulin resistance, and T2DM are conditions with elevated blood concentrations of one or more BCAA, branched-chain keto acids, and/or short-chain carnitine esters derived from partial BCAA catabolism in human adults. Since insulin resistance is more prevalent in overweight and obese individuals compared to lean persons, it is important to consider that the high circulating BCAA and derivatives in the aforementioned studies were also tracking insulin resistance and not just adiposity per se [26].

Moore et al. [13] showed that 3-methyl-2-oxobutyrate $(\uparrow), a$-hydroxyisovalerate $(\uparrow), 4$-methyl-2-oxopentanoate $(\uparrow)$, and 3 -hydroxyisobutyrate $(\uparrow)$ are associated with the BMI. These short-chain acyls are degradation products of BCAA and are converted to short-chain $\mathrm{CN}$. Neither BCAA nor short-chain $\mathrm{CN}$ are likely to be responsible for the adverse effects, but the keto acids which are generated during BCAA degradation may have pathological consequences. Further studies should increase the focus on these keto acids.

\section{Amino Acids}

Six articles identified AA other than BCAA as indicative of obesity; these are: the aromatic AA phenylalanine $(\uparrow)[12,13](\downarrow)[19]$, tyrosine $(\uparrow)[12-14]$, and tryptophan $(\uparrow)[12,14]$; the sulfur-containing AA methionine $(\downarrow)$ [11]; the cyclic AA proline $(\downarrow)$ [11]; the aliphatic AA gly- 
cine $(\uparrow)$ [9] ( $\downarrow)$ [13] and alanine $(\uparrow)$ [12]; the acidic AA (and their amides) glutamine $(\uparrow)[9](\downarrow)$ [11], glutamate $(\uparrow)$ [13], glutamate/glutamine $(\uparrow)$ [12], aspartate/asparagine $(\uparrow)$ [12], and asparagine $(\downarrow)$ [13]; the basic AA arginine $(\uparrow)$ [12] and histidine $(\downarrow)$ [13]; the hydroxyl AA serine $(\downarrow)[19]$, and the nonproteinogenic AA kynurenine $(\uparrow)$. Furthermore, there were differences in the acetylation product $\mathrm{N}$-acetylglycine $(\downarrow)$ and the AA degradation products 3-(4-hydroxyphenyl) lactate $(\uparrow)$ and 2-hydroxybutyrate (AHB) $(\uparrow)$ [13].

In a metabolomics analysis of serum from 38- to 52-year-old participants, Xu et al. [27] found that several AA including alanine, proline, phenylalanine, and glutamine were raised in insulin-resistant subjects. This provides another 'hint' that some biomarkers for the obese state are possible early markers for insulin resistance.

Several articles found associations between aromatic acids like phenylalanine [28] and insulin secretion or T2DM. Würtz et al. [29], for example, concluded that elevated branched-chain and aromatic AA levels precede the development of insulin resistance already in early adulthood.

Adams [26] reviewed that increased circulating concentrations of phenylalanine and tyrosine have been reported in the obese, insulin-resistant, or T2DM state in humans. He concluded that changes in these metabolites often go hand in hand.

\section{Lipids}

Lipids, another class of metabolites associated with obesity in some publications, can be determined as a molecular species or through the FA composition of single lipid classes such as glycerophopholipids [30, 31], NEFA [32], and acylglycerols [33], as well as that of all lipid classes (total FA; tFA) [34]. Thus, comparison of the results of different reports is challenging.

Okada et al. [35] found alterations in the composition of the tFA C14:0 $(\uparrow), C 16: 0(\uparrow), C 16: 1 n-7(\uparrow), C 18: 1 n-9$ $(\uparrow), C 20: 1 n-9(\uparrow), C 20: 3 n-6(\uparrow), C 18: 3 n-3(\uparrow)$, and C18:2n-6( $\downarrow$ ), as well as C20:2n-6 $(\downarrow)$, while Newgard et al. [12] showed increases in the absolute concentration of most analyzed tFA. Thus, two different assumptions can be made. First, the absolute FA concentration in the blood is increased in obese subjects (this is in accordance with elevated triacylglycerol levels) [33], and second, and maybe more importantly, the composition of FA in the blood changes. Elevated percentages of monounsaturated FA (MUFA) reflect an increase in stearoyl-CoA desaturase (SCD) activity [35], and this means a higher rate of conversion from saturated FA to MUFA. SCD is a $\Delta 9$ desaturase. Increased SCD activity and higher levels of MUFA were found in many publications [36, 37]. Another alteration of FA metabolism is represented by alterations of polyunsaturated FA (PUFA) percentages. Warensjö et al. [38] analyzed the FA composition of serum $C E$ and showed a positive correlation of $\Delta 6$ desaturase as well as a negative correlation of $\Delta 5$ desaturase activity with markers for obesity in adults by calculating the ratios of the corresponding FA [40]. They also showed an increase in $\Delta 9$ desaturase activity, which is in agreement with the results of Okada et al. [35]. A decrease in $\Delta 5$ desaturase in obese subjects would result in a stronger increase in C20:3n 6 compared to C20:4n6. This is also in agreement with Okada et al. [35], who found significantly higher levels of C20:3n6 percentages in obese subjects and no significant difference for C20:4n 6 between obese and control subjects.

An additional paper, which analyzed the FA composition of phospholipids (PL), found the concentrations of C22:6n-3 ( $\downarrow), C 24: 1 n-9(\uparrow)$, the C24:1n-9-to-C24:0 ratio $(\uparrow), C 20: 0(\uparrow)$, and C22:0 $(\uparrow)$ to be altered in females and that of $\mathrm{C} 20: 0(\uparrow)$ and the $\mathrm{C} 24: 1 \mathrm{n}-9$-to-C24:0 ratio $(\uparrow)$ to be altered in males [41], which also reflects increased SCD activity. Interestingly, they found only small changes in PUFA percentages (table 1). PL composition was also determined by Kim et al. [14], who confirmed the decreased $\Delta 5$ desaturase activity which was especially influenced by higher levels of 20:3n6. Thus, one should focus on C20:3n6 (dihomo- $\gamma$-linolenic acid) in further studies and not only on C20:4 and C22:6. Kim et al. [14] showed minor effects on MUFA, $\Delta 9$ desaturase activity, and other PUFA.

Another lipid class which is discussed in obesity research is plasma NEFA, reflecting the FA composition and activity of adipose tissue for certain FA species [32]. Newgard et al. [12] reported increased levels of NEFA C14:0 ( $\uparrow), C 16: 0(\uparrow), C 16: 1(\uparrow), C 18: 1(\uparrow)$, and C20:4n6 $(\uparrow)$ but no change in C18:0, C18:2n-6, or C18:3n-3 in obese participants [12], while Zeng et al. [19] showed no difference for any determined NEFA. The fact that obesity and an increased fat mass do not necessarily result in a greater release of NEFA from adipose tissue or higher NEFA levels was systematically reviewed by Karpe et al. [40]. The authors reviewed studies which were related to 'metabolomics'. Thus, articles that just dealt with FA composition in relation to obesity were not included during the review process.

Aside from FA composition, the determination of molecular species is becoming more important, especially for LPC and PC. Four articles found significant dis- 
turbed values for LPC and PC species. Oberbach et al. [9]

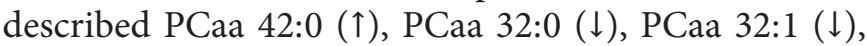
and PCaa 40:5 $(\downarrow)$ as possible biomarkers for obesity. Wahl et al. [11] showed significant differences for PCaa

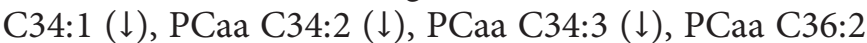

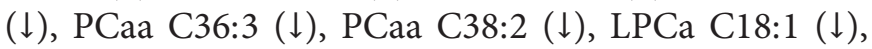

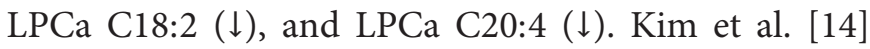
found LPC C14:0 ( $\uparrow)$, LPC C16:0 ( $\uparrow)$, LPC C18:0 ( $\uparrow)$, and LPC C18:1 $(\downarrow)$ to be different between lean and obese subjects. Pietiläinen et al. [41] found PC 38:3( $\downarrow$ ), PC O-16:0/20:3 $(\downarrow)$, PC 38:2 $(\downarrow)$, GPEtn O-36:3 $(\downarrow)$, GPEtn 38:1 $(\downarrow)$, PC 34:3 $(\downarrow)$, PC O-38:7 $(\downarrow)$, GPEtn 42:6 $(\downarrow)$, PC 40:6 $(\downarrow)$, PC O-34:1 $(\downarrow)$, PC 36:4 $(\uparrow)$, PC 38:6 $(\uparrow)$, PC

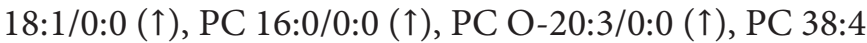

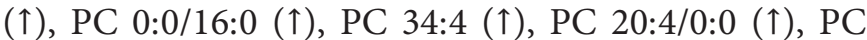

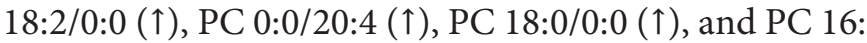
0/20:4 ( $\uparrow$.

The results seem to be inconsistent and their interpretation very complex in the context of this review and therefore a global summary cannot be given. Furthermore, the data are complex in relation to the FA content since, for example, PC $36: 3$ is the sum parameter for PC 16:0/20:3, PC 14:0/22:3, PC 16:1/20:2, PC 18:0/18:3, and PC 18:1/18:2.

\section{Limitations}

One limitation of the described studies is that the different studies of metabolomics were undertaken in subjects of differing ages, and there might be age-related differences in metabolism. Besides that, growth might have an impact on metabolism, especially in relation to the metabolic pathway of BCAA. Mihalik et al. [21] and Wahl et al. [11] argue that there is some evidence for early adaptive mechanisms in children, who can preserve a normal BCAA metabolism even in the obese state. Biomarker studies should be interpreted with respect to this suggestion.

Another restriction could be the definition of obesity. For a long time, the BMI was the standard measurement criterion, with a cutoff point of 30 , but recently a few limitations of this measurement have become apparent, e.g. the fact that the Asian population does not fit the criteria for the BMI borderlines [43]. Currently, more and more research is being conducted using measures of body composition including the waist-to-hip ratio, the DEXA, and skinfold measurements as indicators of the obese state in humans.

In most cases, sex differences should be interpreted more clearly because some studies suggested that there are differences between men and women according to the surrogate measurements BMI and waist circumference. Camhi et al. [44], for example, found that there were significant differences for all fat depots for a given level of BMI or waist circumference between sexes. In some studies, the gender of the participants was not reported or the study was confined to male subjects (table 2). Many of the studies were conducted using a Biocrates kit and therefore resulted in similar metabolic findings and conclusions. Most of the studies had small sample sizes, so the effects measured may have been due to randomness. All studies were case-control or crosssectional studies, so no causality but rather only associations could be concluded.

The strength of this review is the fact that it provides a very comprehensive overview of the current state of the knowledge and research on biomarkers for obesity in adults as well as in children. The metabolites suggested as biomarkers in the presented studies represent very similar metabolic pathways that could be disturbed in the obese state, since most of the literature on this topic has discovered alterations in the BCAA concentrations and in FA oxidation.

\section{Conclusion}

Obesity has become a global public health burden. Since consumption of the 'Western diet' is spreading across the world, the burden is likely to increase over the next years, especially if no preventive strategies are discovered, based on a foundation of knowledge of the underlying mechanisms.

Metabolomics is a tool with the potential for major influence on public health preventive strategies since it provides background knowledge of the underlying mechanisms of obesity and associated diseases such as insulin resistance and T2DM.

The metabolites that have repeatedly been identified in several studies are BCAA, i.e. isoleucine, leucine, and valine, the AA glutamine, methionine, and phenylalanine, the LPC C18:1, and several CN. The use of BCAA as biomarkers for obesity should be handled with care since BCAA are also indicative of and possible biomarkers for insulin resistance and T2DM [42]. Elevated levels of BCAA may be early signs of later development of one of these diseases. Future studies should focus on alterations in BCAA metabolism. More research on the biomarkers already identified is needed. 


\section{Acknowledgement}

The research leading to these results received funding from the European Union's 7th Framework Programme (FP7/2007-2013), EarlyNutrition project, under grant agreement No. 289346. This paper does not necessarily reflect the views of the Commission and in no way anticipates the future policy in this area.

\section{Disclosure Statement}

The authors have no conflicts of interest to disclose.

\section{References}

1 Ebbeling CB, Pawlak DB, Ludwig DS: Childhood obesity: public-health crisis, common sense cure. Lancet 2002;360:473-482.

2 James PT, Rigby N, Leach R: The obesity epidemic, metabolic syndrome and future prevention strategies. Eur J Cardiovasc Prev Rehabil 2004;11:3-8.

-3 Guilherme A, Virbasius JV, Puri V, Czech MP: Adipocyte dysfunctions linking obesity to insulin resistance and type 2 diabetes. Nat Rev Mol Cell Biol 2008;9:367-377.

4 Sowers JR: Obesity as a cardiovascular risk factor. Am J Med 2003;115(suppl 8A):37S41S.

5 Grundy SM, Cleeman JI, Daniels SR, Donato KA, Eckel RH, Franklin BA, Gordon DJ, Krauss RM, Savage PJ, Smith SC Jr, Spertus JA, Fernando C: Diagnosis and management of the metabolic syndrome: an American Heart Association/National Heart, Lung, and Blood Institute scientific statement - executive summary. Crit Pathw Cardiol 2005;4: 198-203.

6 Koletzko B, von Kries R, Closa R, Escribano J, Scaglioni S, Giovannini M, Beyer J, Demmelmair H, Anton B, Gruszfeld D, Dobrzanska A, Sengier A, Langhendries JP, Rolland Cachera MF, Grote V: Can infant feeding choices modulate later obesity risk? Am J Clin Nutr 2009;89:1502S-1508S.

7 Weinberger KM: Metabolomics in diagnosing metabolic diseases (in German). Ther Umsch 2008;65:487-491.

8 Griffiths WJ, Koal T, Wang Y, Kohl M, Enot DP, Deigner HP: Targeted metabolomics for biomarker discovery. Angewandte Chemie Int Ed Engl 2010;49:5426-5445.

-9 Oberbach A, Bluher M, Wirth H, Till H, Kovacs $P$, Kullnick Y, Schlichting N, Tomm JM, Rolle-Kampczyk U, Murugaiyan J, Binder H, Dietrich A, von Bergen M: Combined proteomic and metabolomic profiling of serum reveals association of the complement system with obesity and identifies novel markers of body fat mass changes. J Proteome Res 2011; 10:4769-4788.

10 Mihalik SJ, Goodpaster BH, Kelley DE, Chace DH, Vockley J, Toledo FG, DeLany JP: Increased levels of plasma acylcarnitines in obesity and type 2 diabetes and identification of a marker of glucolipotoxicity. Obesity (Silver Spring) 2010;18:1695-1700.
11 Wahl S, Yu Z, Kleber M, Singmann P, Holzapfel C, He Y, Mittelstrass K, Polonikov A, Prehn C, Romisch-Margl W, Adamski J, Suhre K, Grallert H, Illig T, Wang-Sattler R, Reinehr T: Childhood obesity is associated with changes in the serum metabolite profile. Obes Facts 2012;5:660-670.

12 Newgard CB, An J, Bain JR, Muehlbauer MJ, Stevens RD, Lien LF, Haqq AM, Shah SH, Arlotto M, Slentz CA, Rochon J, Gallup D, Ilkayeva O, Wenner BR, Yancy WS Jr, Eisenson H, Musante G, Surwit RS, Millington DS, Butler MD, Svetkey LP: A branched-chain amino acid-related metabolic signature that differentiates obese and lean humans and contributes to insulin resistance. Cell Metab 2009;9: 311-326.

13 Moore SC, Matthews CE, Sampson JN, Stolzenberg-Solomon RZ, Zheng W, Cai Q, Tan YT, Chow WH, Ji BT, Liu DK, Xiao Q, Boca SM, Leitzmann MF, Yang G, Xiang YB, Sinha R, Shu XO, Cross AJ: Human metabolic correlates of body mass index. Metabolomics 2014;10:259-269.

14 Kim JY, Park JY, Kim OY, Ham BM, Kim HJ, Kwon DY, Jang Y, Lee JH: Metabolic profiling of plasma in overweight/obese and lean men using ultra performance liquid chromatography and Q-TOF mass spectrometry (UPLCQ-TOF MS). J Proteome Res 2010;9:43684375.

15 Houten SM, Wanders RJ: A general introduction to the biochemistry of mitochondrial fatty acid beta-oxidation. J Inherit Metab Dis 2010;33:469-477.

16 Samuel VT, Petersen KF, Shulman GI: Lipidinduced insulin resistance: unravelling the mechanism. Lancet 2010;375:2267-2277.

17 Platell C, Kong SE, McCauley R, Hall JC: Branched-chain amino acids. J Gastroenterol Hepatol 2000;15:706-717.

18 Paul HS, Adibi SA: Effect of carnitine on branched-chain amino acid oxidation by liver and skeletal muscle. Am J Physiol 1978; 234:E494-E499.

19 Zeng M, Liang Y, Li H, Wang M, Wang B, Chen X, Zhou N, Cao D, Wu J: Plasma metabolic fingerprinting of childhood obesity by GC/MS in conjunction with multivariate statistical analysis. J Pharm Biomed Anal 2010; 52:265-272.
20 McCormack SE, Shaham O, McCarthy MA, Deik AA, Wang TJ, Gerszten RE, Clish CB, Mootha VK, Grinspoon SK, Fleischman A: Circulating branched-chain amino acid concentrations are associated with obesity and future insulin resistance in children and adolescents. Pediatr Obes 2013;8:52-61.

21 Mihalik SJ, Michaliszyn SF, de las Heras J, Bacha F, Lee S, Chace DH, DeJesus VR, Vockley J, Arslanian SA: Metabolomic profiling of fatty acid and amino acid metabolism in youth with obesity and type 2 diabetes: evidence for enhanced mitochondrial oxidation. Diabetes Care 2012;35:605-611.

22 Cheng Y, Meng Q, Wang C, Li H, Huang Z, Chen S, Xiao F, Guo F: Leucine deprivation decreases fat mass by stimulation of lipolysis in white adipose tissue and upregulation of uncoupling protein 1 (UPC1) in brown adipose tissue. Diabetes 2010;59:17-25.

23 Goichon A, Chan P, Lecleire S, Coquard A, Cailleux AF, Walrand S, Lerebours E, Vaudry D, Dechelotte P, Coeffier M: An enteral leucine supply modulates human duodenal mucosal proteome and decreases the expression of enzymes involved in fatty acid beta-oxidation. J Proteomics 2013;78:535-544.

24 Suryawan A, Davis TA: Regulation of protein synthesis by amino acids in muscle of neonates. Front Biosci 2011;16:1445-1460.

25 Melnik BC: Excessive leucine-mTORC1-signalling of cow milk-based infant formula: the missing link to understand early childhood obesity. J Obes 2012;2012:197653.

26 Adams SH: Emerging perspectives on essential amino acid metabolism in obesity and the insulin-resistant state. Adv Nutr 2011;2:445456.

27 Xu F, Tavintharan S, Sum CF, Woon K, Lim SC, Ong CN: Metabolic signature shift in type 2 diabetes mellitus revealed by mass spectrometry-based metabolomics. J Clin Endocrinol Metab 2013;98:E1060-E1065.

- 28 Floegel A, Stefan N, Yu Z, Muhlenbruch K, Drogan D, Joost HG, Fritsche A, Haring HU, Hrabe de Angelis M, Peters A, Roden M, Prehn C, Wang-Sattler R, Illig T, Schulze MB, Adamski J, Boeing H, Pischon T: Identification of serum metabolites associated with risk of type 2 diabetes using a targeted metabolomic approach. Diabetes 2013;62:639-648. 
29 Würtz P, Soininen P, Kangas AJ, Ronnemaa T, Lehtimaki T, Kahonen M, Viikari JS, Raitakari OT, Ala-Korpela M: Branched-chain and aromatic amino acids are predictors of insulin resistance in young adults. Diabetes Care 2013;36:648-655.

30 Glaser C, Demmelmair H, Koletzko B: Highthroughput analysis of fatty acid composition of plasma glycerophospholipids. J Lipid Res 2010;51:216-221.

31 Uhl O, Glaser C, Demmelmair H, Koletzko B: Reversed phase LC/MS/MS method for targeted quantification of glycerophospholipid molecular species in plasma. J Chromatogr B Analyt Technol Biomed Life Sci 2011;879: 3556-3564.

- 32 Hellmuth C, Demmelmair H, Schmitt I, Peissner W, Bluher M, Koletzko B: Association between plasma nonesterified fatty acids species and adipose tissue fatty acid composition. PLoS One 2013;8:e74927.

- 33 Hellmuth C, Uhl O, Segura-Moreno M, Demmelmair H, Koletzko B: Determination of acylglycerols from biological samples with chromatography-based methods. J Sep Sci 2011;34:3470-3483.

34 Glaser C, Demmelmair H, Koletzko B: Highthroughput analysis of total plasma fatty acid composition with direct in situ transesterification. PLoS One 2010;5:e12045.
35 Okada T, Furuhashi N, Kuromori Y, Miyashita M, Iwata F, Harada K: Plasma palmitoleic acid content and obesity in children. Am J Clin Nutr 2005;82:747-750.

36 Caron-Jobin M, Mauvoisin D, Michaud A, Veilleux A, Noel S, Fortier MP, Julien P, Tchernof A, Mounier C: Stearic acid content of abdominal adipose tissues in obese women. Nutr Diabetes 2012;2:e23.

37 Garaulet M, Hernandez-Morante JJ, Tebar FJ, Zamora S: Relation between degree of obesity and site-specific adipose tissue fatty acid composition in a Mediterranean population. $\mathrm{Nu}$ trition 2011;27:170-176.

38 Warensjö E, Ohrvall M, Vessby B: Fatty acid composition and estimated desaturase activities are associated with obesity and lifestyle variables in men and women. Nutr Metab Cardiovasc Dis 2006;16:128-136.

39 Karlsson M, Marild S, Brandberg J, Lonn L, Friberg P, Strandvik B: Serum phospholipid fatty acids, adipose tissue, and metabolic markers in obese adolescents. Obesity (Silver Spring) 2006;14:1931-1939.

40 Karpe F, Dickmann JR, Frayn KN: Fatty acids, obesity, and insulin resistance: time for a reevaluation. Diabetes 2011;60:2441-2449.
41 Pietiläinen KH, Sysi-Aho M, Rissanen A, Seppanen-Laakso T, Yki-Jarvinen $\mathrm{H}$, Kaprio J, Oresic M: Acquired obesity is associated with changes in the serum lipidomic profile independent of genetic effects - a monozygotic twin study. PLoS One 2007;2:e218.

42 Newgard CB: Interplay between lipids and branched-chain amino acids in development of insulin resistance. Cell Metab 2012;15:606614.

43 Goh VH, Tain CF, Tong TY, Mok HP, Wong MT: Are BMI and other anthropometric measures appropriate as indices for obesity? A study in an Asian population. J Lipid Res 2004;45:1892-1898.

44 Camhi SM, Bray GA, Bouchard C, Greenway FL, Johnson WD, Newton RL, Ravussin E, Ryan DH, Smith SR, Katzmarzyk PT: The relationship of waist circumference and BMI to visceral, subcutaneous, and total body fat: sex and race differences. Obesity (Silver Spring) 2011;19:402-408.

45 Netzer M, Kugler KG, Muller LA, Weinberger KM, Graber A, Baumgartner C, Dehmer M: A network-based feature selection approach to identify metabolic signatures in disease. J Theor Biol 2012;310:216-222. 